\title{
Increased nitro-oxidative stress toxicity as a major determinant of increased blood pressure in mood disorders.
}

Kamila Landucci Bonifácio ${ }^{1,3}$, Décio Sabbatini Barbosa ${ }^{1,2,3}$, Estefânia Gastaldello Moreira ${ }^{3}$, Carine Farias Coneglian ${ }^{1,3}$, Heber Odebrecht Vargas ${ }^{4}$, Sandra Odebrecht Vargas Nunes ${ }^{3,4}$, Juliana Brum Moraes $^{1}$, Michael Maes ${ }^{5,6,7 *}$

${ }^{1}$ Health Sciences Graduation Program, Health Sciences Center, State University of Londrina, Londrina, Paraná, Brazil

${ }^{2}$ Department of Clinical Analysis and Toxicological, State University of Londrina

${ }^{3}$ Graduation Program in Health Sciences, State University of Londrina, Londrina, PR, Brazil

${ }^{4}$ Department of Psychiatry, Health Sciences Center, State University of Londrina, Londrina, Paraná, Brazil

${ }^{5}$ Department of Psychiatry, Faculty of Medicine, King Chulalongkorn Memorial Hospital, Bangkok, Thailand

${ }^{6}$ Department of Psychiatry, Medical University of Plovdiv, Plovdiv, Bulgaria

${ }^{7}$ IMPACT Strategic Research Centre, Deakin University, Geelong, VIC, Australia

Corresponding authors:

Prof. Dr. Michael Maes, M.D., Ph.D.

Department of Psychiatry

Faculty of Medicine 
Chulalongkorn University

Bangkok

Thailand.

email: dr.michaelmaes@hotmail.com.

https//:scholar.google.co.th/citations?user=1wzMZ7UAAAAJ\&hl=th\&oi=ao

Kamila Landucci Bonifácio: kamilalondrina@hotmail.com

Décio Sabbatini Barbosa: sabbatini2011@ @hotmail.com

Estefânia Gastaldello Moreira: egmoreira22@ hotmail.com

Carine Farias Coneglian: carine_coneglian@yahoo.com.br

Heber Odebrecht Vargas: hebervargas@ @ercomtel.com.br

Sandra Odebrecht Vargas Nunes: $\underline{\text { sandranunes @ sercomtel.com.br }}$

Juliana Brum Moraes: julianabrumpsiq@gmail.com

Michael Maes: dr.michaelmaes@hotmail.com 


\begin{abstract}
BACKGROUND: Hypertension, atherogenicity and insulin resistance are major risk factors of cardiovascular disorder (CVD), which shows a strong comorbidity with major depression (MDD) and bipolar disorder (BD). Activated oxidative and nitrosative stress (O\&NS), inflammatory pathways, and increased atherogenicity are shared pathways underpinning CVD and mood disorders.
\end{abstract}

METHODS: The current study examined the effects of lipid hydroperoxides (LOOH), superoxide dismutase (SOD), nitric oxide metabolites (NOx), advanced oxidation protein products (AOPP), and malondialdehyde (MDA) on systolic (SBP) and diastolic (DBP) blood pressure in 96 mood disordered patients and 60 healthy controls.

RESULTS: A large part of the variance in SBP (31.6\%) was explained by the regression on a $\mathrm{z}$ unit-weighted composite score (based on LOOH, AOPP, SOD, NOx) reflecting nitro-oxidative stress toxicity (NOSTOX), coupled with highly sensitive C-reactive protein, body weight and use of antihypertensives. Increased DBP was best predicted (23.8\%) by body mass index and NOSTOX. The most important O\&NS biomarkers predicting an increased SBP were in descending order of significance: LOOH, AOPP and SOD. Higher levels of the atherogenic index of plasma, HOMA2 insulin resistance index and basal thyroid-stimulating hormone also contributed to increased SBP independently from NOSTOX. Although there were no significant changes in SBP/DBP in mood disorders, the associations between NOSTOX and blood pressure were significant in patients with mood disorders but not in healthy controls. 
CONCLUSIONS: Activated O\&NS pathways including increased lipid peroxidation and protein oxidation, which indicates hypochlorous stress, are the most important predictors of an increased $\mathrm{BP}$, especially in patients with mood disorders.

Keywords: major depression, oxidative and nitrosative stress, antioxidants, inflammation, neuroimmune, biomarkers 


\section{Introduction}

Hypertension is the most common risk factor that contributes to cardiovascular disorder (CVD) and its morbidity and mortality (Kearney et al., 2005). About $90 \%$ of hypertension cases are classified as essential hypertension with unknown cause (Dinh et al., 2014). There is significant comorbidity between hypertension or CVD and mood disorders either major depressive episode (MDD) or bipolar disorder (BD) (Goldstein et al., 2015). Hypertension and depression increase the risk of incident CVD and accelerate the progression of CVD (Baronaite-Dudoniene et al., 2015). Moreover, a recent meta-analysis demonstrated a $42 \%$ increased risk of hypertension in depressed patients, especially in those with a diagnosis made three years earlier (Rubio-Guerra et al., 2013). MDD results in a 1.3-fold increased risk of hypertension (Boal et al., 2016) whilst BD is associated with a 1.5- to 2.5-fold increased risk of CVD mortality and hypertension (Ösby et al., 2001).

This strong comorbidity between CVD and hypertension and mood disorders may be explained by shared pathophysiological processes including activated immune-inflammatory pathways, increased oxidative and nitrosative stress (O\&NS), lowered levels of antioxidants, increased atherogenicity and maybe insulin resistance (de Melo et al., 2017; Maes et al., 2011b). Increased plasma levels of oxidative and nitrosative stress (O\&NS) biomarkers are frequently observed in MDD and BD (Liu et al., 2015; Maes et al., 2019a, 2011a). Important O\&NS biomarkers are increased levels of superoxide dismutase (SOD) indicating a compensatory mechanism to neutralize reactive oxygen species (ROS), lipid hydroperoxides (LOOH), indicating lipid peroxidation, malondialdehyde (MDA), indicating aldehyde formation following lipid peroxidation, advanced oxidation protein products (AOPP), indicating protein oxidation as a 
consequence of chlorinative stress, and increased levels of nitric oxide metabolites (NOx) indicating increased nitrative and nitrosative stress (Liu et al., 2015; Maes et al., 2011a). Moreover, mood disorders are also characterized by lowered levels of antioxidants including high-densitylipoprotein (HDL) cholesterol, paraoxonase 1 (PON1) activity, catalase, as well as vitamin E (Liu et al., 2015; Maes et al., 2011a, 2011b). The same activated inflammatory and O\&NS pathways are also associated with CVD and in fact are etiological factors in increased atherogenicity (Berk et al., 2011; Maes et al., 2011b). Moreover, serum reactive oxygen metabolites correlate with brain inflammatory markers, including high-sensitivity C-reactive protein (hsCRP) and endothelial function (flow-mediated dilation) and predict endothelial damage and CVD (Sugiura et al., 2011). Increased levels of oxidative stress biomarkers are also closely associated with increased carotid intima-media thickness, an indication of atherosclerosis (Montezano et al., 2015; Montezano and Touyz, 2012).

There is also some evidence that patients with hypertension show excess ROS generation, decreased antioxidant defenses and increased oxidative stress toxicity (Montezano et al., 2015; Montezano and Touyz, 2014). Hypertensive patients show reduced activity of key antioxidant enzymes including SOD, glutathione peroxidase, and catalase (Ward et al., 2004). Decreased levels of vitamins A, C, and E and biomarkers of oxidative stress are associated with (untreated) hypertension (Montezano et al., 2015; Montezano and Touyz, 2014; Ward et al., 2004). In patients with essential hypertension, systolic and diastolic blood pressure assessments correlate positively with endothelial dysfunction in association with increased vascular ROS production, oxidative stress toxicity, and vascular inflammation (Ahmad et al., 2013; Carrizzo et al., 2013; Ward et al., 2004). 
Approximately $30 \%$ of subjects with a diagnosis of hypertension show indicants of insulin resistance (Gupta et al., 2019; Ormazabal et al., 2018) and depressed people have a 37\%-60\% increased risk of developing diabetes (Fugger et al., 2019; Yu et al., 2015). Moreover, most patients with diabetes have multiple comorbidities, especially hypertension and CVD (Fugger et al., 2019). Some (Calkin et al., 2015) but not all authors (Bonifácio et al., 2017; Shen and Bergquist-Beringer, 2013) showed that insulin resistance and type 2 diabetes (T2DM) are common among bipolar disorder patients and are associated with an unfavorable clinical course and poor treatment outcome (Kan et al., 2013). Baseline levels of thyroid stimulating hormone (TSH) are positively associated with systolic and diastolic blood pressure and hypertension (Hildrum et al., 2007).

Nevertheless, there are no data whether hypertension in mood disorders is associated with increased O\&NS above and beyond the effects of atherogenicity, insulin resistance and basal TSH. Hence, the aim of the present study was to delineate the associations between blood pressure and SOD, LOOH, MDA, AOPP, catalase, PON1 and HDL-cholesterol among clinically stable patients with MDD and BD and healthy controls (HCs). The a priori hypotheses are that mood disorders are accompanied by increased blood pressure and that the latter is accompanied by activated O\&NS pathways and lowered antioxidant levels.

Subjects and Methods

\section{Participants}

In this cross-sectional study we included 66 healthy controls (HCs) and 96 patients with mood disorders, namely 37 patients with MDD and 59 with BP. All participants were Brazilian of 
both genders and aged 20 to 60 years old. All participants with mood disorders were outpatients admitted to the Psychiatry outpatient clinics at the University Hospital of the Universidade Estadual de Londrina (UEL), Parana, Brazil. They were all in remission or partial remission and the index episode in BD patients was not of (hypo)manic polarity. The HC sample was derived from the same catchment area. The following exclusion criteria were applied for patients and controls: a) subjects with medical illness, including HIV infection, hepatitis $\mathrm{B}$ and $\mathrm{C}$ virus infection, neuro-immune and neurodegenerative disorders (e.g. Parkinson's disease, Alzheimer's disease, multiple sclerosis,), chronic kidney disease, heart failure, stroke, chronic obstructive pulmonary disease, adrenal and thyroid disorders, cancer, autoimmune diseases such as rheumatoid arthritis and type 1 diabetes, b) subjects with other axis-1 diagnoses according to DSMIV-TR criteria, including schizophrenia, schizo-affective disorder, autism, psycho-organic syndromes, c) subjects who were treated with interferon, glucocorticoids, antioxidants such as Nacetylcysteine, herbal supplements and omega-3 polyunsaturated fatty acids during the past 4 weeks before to study enrollment, and d) pregnant and lactating women. Some patients with MDD and BD were treated with antipsychotics $(n=27)$, antidepressants $(n=44)$, anticonvulsants $(n=26)$, lithium $(n=19)$, antihypertensives $(n=35)$ and statins $(n=18)$. All participants provided written informed consent to take part in the current study, whose experimental procedures were previously approved by the Research Ethics Committee at UEL (protocol number: CAAE 34935814.2.0000.5231).

\section{Methods}


The clinical diagnosis of MDD and bipolar type 1 (BP1) and type 2 (BP2) was made by a research psychiatrist using the validated Brazilian Portuguese version of the structured clinical interview for the DSM-IV interview (SCID) axis I (Del-Ben et al., 2001) in accordance to the Diagnostic and Statistical Manual of Mental Disorders, 4th Edition, Text Revision (DSM-IV-TR) diagnostic criteria (American Psychiatric Association, 2000). Moreover, all participants completed a semi-structured interview comprising socio-demographic and clinical data. We used the 17-item Hamilton Depression Rating Scale (HAM-D) to assess severity of depression, translated and adapted for use with Brazilian individuals (Moreno and Moreno, 1998).

Systolic and diastolic blood pressure (SBP and DBP) were assessed using a mercury sphygmomanometer on the right arm and we used the mean value of two measurements carried out 5 min apart. We measured body weight using a digital scale with an accuracy of $0.1 \mathrm{~kg}$, and body height using a portable wooden stadiometer with an accuracy of $0.1 \mathrm{~cm}$. Body mass index (BMI) was assessed using the following formula: weight (in $\mathrm{kg}$ ) divided by the square of height (in $\mathrm{m}^{2}$ ). The diagnosis of metabolic syndrome (MetS) was made according to the International Diabetes Federation criteria (Alberti et al., 2005), namely presence of three out of the following criteria: (a) abdominal obesity (waist circumference $\geq 90 \mathrm{~cm}$ for men and $\geq 80 \mathrm{~cm}$ for women in South Asian and South Americans and $\geq 94.0 \mathrm{~cm}$ for men and $\geq 80.0 \mathrm{~cm}$ for women in Caucasians); (b) low HDL-cholesterol ( $<40 \mathrm{mg} / \mathrm{dL}$ in men and $<50 \mathrm{mg} / \mathrm{dL}$ in women) or use of hypolipidemic drugs; (c) hypertriglyceridemia (triglycerides $>150 \mathrm{mg} / \mathrm{dL}$ ) or use of hypolipidemic agent; (d) increased fasting glucose $(>100 \mathrm{mg} / \mathrm{dL})$ or use of oral antidiabetic medications; (e) increased average blood pressure $(130 / 85 \mathrm{~mm} \mathrm{Hg})$ or currently taking antihypertensive medication. The diagnosis of nicotine dependence was made using DSM-IV-TR criteria. 
Assays

Peripheral fasting (12 hours) blood was sampled at 8 a.m. the same day as the diagnosis was made and clinical data were collected. We measured the concentrations of LOOH, NOx, MDA, and AOPP, and the activities of superoxide dismutase (SOD), catalase (CAT) and paraoxonase 1 (PON-1) as explained previously (Bonifácio et al., 2017; Maes et al., 2019a, 2018). LOOH was assayed by chemiluminescence (CL-LOOH) (Flecha et al., 1991; Panis et al., 2012). NOx levels were assessed indirectly by determining the plasma nitrite concentration using an adaptation of the technique described by Navarro-Gonzalvez et al. (Navarro-Gonzálvez et al., 1998). MDA levels were measured through complexation with two molecules of thiobarbituric acid (TBA) using MDA estimation through high-performance liquid chromatography (Bastos et al., 2012). AOPP was quantified using the method described by Hanasand et al. (Hanasand et al., 2012). SOD activity in erythrocytes was determined using the pyrogallol method described by Marklund and Marklund (Marklund and Marklund, 1974). Measurement of catalase activity was estimated through the difference between the initial reading and the reading conducted 30 seconds after the addition of $200 \mathrm{mM} \mathrm{H} \mathrm{H}_{2} \mathrm{O}_{2} 30 \%$. The total plasmatic activity of PON1 was determined by the method described by Richter et al. (Richter et al., 2008). Insulin and basal thyroid-stimulating hormone levels were determined by MEIA (AXSYM, Abbott® Laboratory, Germany). Serum levels of hsCRP were determined using a turbidimetric assay (ARCHITECT c8000, Architect, Abbott Laboratory, Abbott Park, IL, USA). The inter-assay coefficients of variability for all analytes were less than 5\%. Insulin resistance (HOMA-2IR), was calculated using the HOMA calculator@, Version 2.2.3 (Diabetes Trials Unit of University of Oxford) (Bonifácio et al., 2017). 
Total cholesterol, triglyceride and glucose were assayed using an automated clinical chemistry system (Dimension ${ }^{\circledR}$ RxL, Siemens Healthcare Diagnostics Inc, USA). HDL cholesterol was measured directly with the same methods and without sample pretreatment or centrifugation steps. Low-density lipoprotein (LDL) was calculated using Friedewald's equation (total cholesterol(triglycerides/5+HDL cholesterol).

Raw O\&NS biomarker data were converted in z scores and consequently used to compute z-unit weighted composite scores reflecting different pathways as explained previously (Maes et al., 2019a, 2018). In the current study we examined 5 oxidative stress composite scores, namely LOOH $\quad(z L O O H)+z S O D ; \quad z L O O H+z S O D+z N O x ; \quad z L O O H+z S O D+z N O x+z M D A ;$ zLOOH+zSOD+zNOx+zMDA+zAOPP; and zLOOH+zSOD+zNOx+zAOPP (Maes et al., 2019a) and found that the latter was, in all analyses, the most significant predictor of blood pressure measurements. Therefore, in the current study, we show two indices: a) zLOOH+zSOD+zNOx+zAOPP (denoted as nitro-oxidative stress toxicity or NOSTOX) reflecting increased nitro-oxidative stress leading to protein oxidation (AOPP) via increased ROS and peroxynitrite production coupled with increased myeloperoxidase activity and hypochlorous acid production; and b) zPON1+zCAT+zHDL-c reflecting antioxidant potential (ANTIOX) whereby CAT catalyzes peroxides into water and removes peroxides while PON1 and HDL-cholesterol protect lipids against oxidation and PON1 may neutralize peroxides (Maes et al., 2019a). In addition, we computed two atherogenic indices, namely $\mathrm{z}$ total cholesterol $-\mathrm{z}$ HDL cholesterol (zTC-zHDL, reflecting the Castelli risk index 1) and z triglycerides - z HDL cholesterol (zTRYzHDL, reflecting the atherogenic index of plasma). 
Statistical analyses

We used analysis of contingency tables $\left(\chi^{2}\right.$ test) to assess associations between categorical variables and analysis of variance (ANOVAs) to assess differences in scale variables between different classes. Relationships among continuous variables were calculated employing Pearson's product-moment and partial correlations. Automatic stepwise multivariate regression analysis was conducted to assess the best prediction of the blood pressure data using biomarkers, body weight, BMI, and metabolic syndrome while allowing for the effects of background variables (e.g. age, sex, drug state). All regression analyses were checked for multicollinearity using tolerance and VIF values. Automated stepwise logistic regression analysis was performed in order to assess the best predictors of the group of patients with increased blood pressure. In these regression analyses, we allowed for the possible effects of the above-mentioned confounder variables. Tests were twotailed and an alpha level of 0.05 indicated statistically significant results.

Multilayer perceptron neural network $(\mathrm{NN})$ modeling was employed to delineate the associations between blood pressure entered as output variable and NOSTOX, BMI, body weight, hsCRP, TSH, HOMA2IR, and both atherogenic indices. We trained the model with an automated feedforward architecture model with two hidden layers with up to 8 nodes, gradient descent, 250 epochs and minibatch training. One consecutive step with no decrease in the error term was used as stopping rule. We considered three samples: a) the training sample to estimate the NN parameters (46.67\% of all cases); b) the testing sample to prevent overtraining (20.0\% of all cases), and c) the holdout sample to delineate the predictive validity of the trained model $(33.33 \%)$. Consequently, error and relative error as well as importance and relative importance of the input variables were computed, and the latter were displayed in an importance chart. Finally, we 
computed the association between the predicted values and the actual blood pressure scores using Spearman rank order correlation coefficients. All statistical analyses were conducted using IBM SPSS windows, version 25.

Results

\section{Descriptive statistics}

Table 1 shows the demographic, clinical, blood pressure and biomarker data in the subjects divided into two subsamples, namely those with higher and lower systolic (SBP) + diastolic (DBP) blood pressure. Toward this end we have computed a $\mathrm{z}$-unit weighted composite score of both $\mathrm{z}$ transformed blood pressure measurements as z score SBP (zSBP) + zDBP (zSDBP) and consequently divided the sample in those with higher $\geq$ q75 versus lower $<$ q75 zSDBP values. Subjects with a higher composite zSDBP score show significantly higher values on both blood pressure measurements as compared with those with a lower zSDBP value (see Table 1). We did not use p-corrections to compare differences in clinical and biomarker data between both groups (see Table 1) because the univariate tests are shown in Table 1 and the correlation matrices between the variables are only employed to select the primary explanatory variables and the relevant background variables to be subsequently used in the ultimate multivariate analyses. Nevertheless, Table 1 suggests that there are no significant differences in age, education and income between both groups. Subjects with higher zSDBP values show more men, higher body weight, waist circumference, body mass index and a higher incidence of MetS than those with lower zSDBP values. The NOSTOX index was significantly higher in subjects with increased zSDBP values as compared with those with lower values, while the ANTIOX score was significantly lower. There 
were also significant differences in both lipid indices (reflecting the AIP and Castelli risk index 1), hsCRP, HOMA2IR index and baseline TSH between both study groups. There was no significant association between the zSDBP groups and clinical diagnoses (MDD, BP2, BP1 and controls), TUD and HAM-D. There were no significant associations between the zSDBP groups and use of different types of drugs, except for antihypertensive drugs, which are higher in those with an increased $\mathrm{BP}$, reflecting that patients with increased zSDBP are more likely to be treated with these drugs. Therefore, we decided to perform two types of analyses, namely with and without the inclusion of the use of antihypertensive drugs as an additional confounding variable.

\section{Prediction of SBP/DBP by O\&NS and immune biomarkers}

In order to examine the associations between the different biomarkers and SBP/DBP we have performed automatic stepwise multiple regression analyses with SBP or DBP as dependent variables and the biomarkers, age, sex, body weight, BMI and diagnosis (BD and MDD entered as dummy variables) as explanatory variables, while adjusting (or not) for the use of antihypertensives. Table 2, regression \#1a shows that $28.3 \%$ of the variance in SBP was explained by the regression on NOSTOX, body weight and hsCRP (all positively associated). Figure 1 shows the partial regression of SBP on the NOSTOX score. Introduction of use of antihypertensive drugs (regression \#1b) showed that these drugs increased the prediction by only $3.3 \%$ and that the biomarker data and weight remained significant. Regression \#2a and \#2b show that $23.8 \%$ of the variance in DBP is explained by NOSTOX and BMI, and that entry of antihypertensive drugs improves the prediction by $4.2 \%$. Regression \#3 shows that $33.5 \%$ of the variance in $\mathrm{zSDBP}$ is explained by the regression on NOSTOX, BMI, hsCRP and use of antihypertensives. 
Consequently, we have entered the O\&NS variables separately in regression analyses. $\mathrm{LOOH}(\mathrm{t}=+3.40, \mathrm{p}=0.001)$ was the most significant predictor together with $\mathrm{BMI}(\mathrm{t}=+4.19$, $\mathrm{p}<0.001)$ and antihypertensive drugs $(\mathrm{t}=+3.03, \mathrm{p}=0.003)$ explaining around $28.5 \%$ of the variance in the $\mathrm{zSDBP}$ data $(\mathrm{F}=16.23, \mathrm{df}=3 / 122, \mathrm{p}<0.001)$. The next most significant $\mathrm{O} \& \mathrm{NS}$ predictor variable was AOPP $(\mathrm{t}=+2.66, \mathrm{p}=0.009)$, which together with $\mathrm{BMI}$ and antihypertensive drugs explained $26.7 \%$ of the variance in the $\mathrm{zSDBP}$ data $(\mathrm{F}=14.93, \mathrm{df}=3 / 123, \mathrm{p}<0.001)$. Also, SOD was a significant predictor $(\mathrm{t}=+2.01, \mathrm{p}=0.047)$, while NOx and MDA were not significant.

In order to examine the associations between increased zSDBP values and the different biomarkers, we have performed automatic stepwise binary logistic regression analyses with higher zSDBP values (as defined in table 1) as dependent variable and the biomarkers, age, sex, diagnosis, body weight, BMI and MetS as explanatory variables, while adjusting (or not) for the use of antihypertensives. Table 3 shows the results of the logistic regression analyses. Model \#1 shows that the group with zSDBP values > q75 was significantly predicted by NOSTOX and hsCRP, with $\left(\mathrm{X}^{2}=26.42, \mathrm{df}=2, \mathrm{p}<0.001 ;\right.$ Nagelkerke=0.257) or without $\left(\mathrm{X}^{2}=15.86, \mathrm{df}=2, \mathrm{p}<0.001\right.$; Nagelkerke $=0.161$ ) use of antihypertensive drugs. In this regression analyses, body weight, BMI, MetS, age and sex are not significant.

\section{Effects of HOMA2IR, basal TSH and atherogenicity indices}

In order to examine possible effects of lipid indices, HOMA2IR index, and basal TSH, we performed the same regression analysis as shown in table 2 but now without body weight, BMI and hsCRP as explanatory variables, while introducing the lipid indices, HOMA2IR or basal TSH in the analyses. We found that these biomarkers were significantly associated with BMI or body 
weight and, therefore, introducing BMI/body weight together with these biomarkers would yield inconclusive results in part due to multicollinearity. Thus, a multivariate GLM analysis shows a strong association between $\mathrm{BMI}$ and those three biomarkers $(\mathrm{F}=33.20, \mathrm{df}=3 / 140, \mathrm{p}<0.001)$, while tests for between-subject effects show significant positive associations between BMI and zTRYzHDL $(\mathrm{F}=39.68, \mathrm{df}=1 / 142, \mathrm{p}<0.001)$, HOMA2IR index $(\mathrm{F}=69.84, \mathrm{df}=1 / 142, \mathrm{p}<0.001)$ and basal TSH $(\mathrm{F}=11.87, \mathrm{df}=1 / 142, \mathrm{p}=0.001)$. In addition, correlation analysis showed also a significant and positive correlation between BMI and hsCRP ( $\mathrm{r}=0.503$, $\mathrm{pp}<0.001, \mathrm{n}=153)$.

Table 4, regression \#1 shows that $24.3 \%$ of the variance in SBP was explained by the regression on NOSTOX, zTRY-zHDL and use of antihypertensive drugs (all positively associated). Regression \#2 shows that $22.1 \%$ of the variance in SBP was explained by NOSTOX, use of antihypertensive drugs and HOMA2IR index (positively associated). Regression \#3 shows that also basal TSH was positively associated with SBP together with the NOSTOX index and use of antihypertensives.

\section{Differences between mood disorder patients and controls}

Although the automatic stepwise regressions in Tables 2-4 allowed for the effects of diagnosis (entered as dummy variables reflecting $\mathrm{HC}, \mathrm{BP} 1, \mathrm{BP} 2$ and MDD), these variables were not among the significant predictors. Forced entry showed that these dummy variables did not have a significant effect on any of the blood pressure data. Figure 2 shows the zSDBP, SBP and DBP values (all in z scores) in controls, MDD, BP1 and BP2 patients. Univariate GLM analysis adjusted for age and sex did not show any significant differences in $\mathrm{zSCBP}(\mathrm{F}=0.50, \mathrm{df}=3 / 156, \mathrm{p}=0.681)$, 
SBP $(\mathrm{F}=0.30, \mathrm{df}=3 / 156, \mathrm{p}=0.829)$ and $\mathrm{DBP}(\mathrm{F}=0.73, \mathrm{df}=3 / 156, \mathrm{p}=0.538)$ between the 4 study groups.

We have also examined whether the association between NOSTOX and blood pressure data differed between patients with mood disorders and healthy controls. In controls there were no significant partial correlations (adjusted for age, sex, BMI, body weight and use of antihypertensives) between NOSTOX and SBP ( $\mathrm{r}=0.167, \mathrm{p}=0.384, \mathrm{n}=52)$, DBP $(\mathrm{r}=0.100$, $\mathrm{p}=0.388)$ and $\mathrm{zSDBP}(\mathrm{r}=0.141, \mathrm{p}=0.309)$, whereas in patients with mood disorders significant correlations were found between NOSTOX and SBP $(r=0.384, p=0.001, n=76)$, DBP $(r=0.388$, $\mathrm{p}<0.001)$ and $\mathrm{zSDBP}(\mathrm{r}=0.422, \mathrm{p}<0.001)$. Nevertheless, these differences in correlation coefficients between both study samples were not significant. We have also performed stepwise multiple regression in both patients and controls separately (Table 4). Regression \#4 shows that in normal controls $34.8 \%$ of the variance in zSDBP was explained by the regression on body weight and zTC_zHDL. Regression \#5 shows that in mood disorder patients, 36.9\% of the variance in zSDBP was explained by NOSTOX, body weight and use of antihypertensive drugs.

\section{Effects of background variables on BP data.}

Tables 1-4 show that there were no significant effects of age on the BP data while Table 1 shows a very modest association between gender and the BP groups (higher in males). Table 2-4 show that gender was not among the significant predictors after considering the effects of BMI or body weight and the IO\&NS biomarkers. Table 2 shows the significant positive associations between BP data and body weight or BMI. Although Table 1 shows a modest association between BP groups and MetS, the latter was not included in the final models while body weight or BMI 
were significant predictors (see table 2). Thus, body weight or BMI appear to be more strongly associated with BP than MetS. GLM analysis did not show a significant effect of tobacco use disorder on the $\mathrm{zSDBP}$ data $(\mathrm{F}=0.58, \mathrm{df}=1 / 122, \mathrm{p}=0.447)$. Univariate GLM analyses did not show any significant effects of antidepressants $(\mathrm{F}=0.18, \mathrm{df}=2 / 140, \mathrm{p}=0.837)$, antipsychotics $(\mathrm{F}=0.99$, $\mathrm{df}=2 / 140, \mathrm{p}=0.374)$, lithium $(\mathrm{F}=0.56, \mathrm{df}=2 / 140, \mathrm{p}=0.58)$ and $\operatorname{mood}$ stabilizers $(\mathrm{F}=0.15, \mathrm{df}=2 / 140$, $\mathrm{p}=0.860)$ on the BP data.

\section{Results of neural networks}

Table 5 shows the results of three NN models with zSDBP, SBP, and DBP as output variables. This table shows the network information (number of units, rescaling method, number of hidden layers, number of units in hidden layers 1 and 2, activation functions in the hidden layer and output layer as well as the error term) and model summary (sum of squares error, and relative errors in the three samples) and the correlations between the predicted and actual blood pressure data for each of the three NN models. We trained all neural networks with 8 units, one (DBP) or two (SBP and zSDBP) hidden layers, with 7 units in layer 1 and five (SBP and zSDBP) or three (DBP) units in layer 2. In all three models, hyperbolic tangent was the activation function in the hidden layer, while identity (zSDBP and DBP) or hyperbolic tangent (SBP) were the activation functions in the output layer. In the models, the sums of squares error terms were lower in the testing than in the training set indicating that the trained models learnt to generalize from the trend. We have deleted age and sex from the final analyses as these input data were always nonsignificant. Figure 3 shows the (relative) importance chart indicating that body weight and NOSTOX, were the major determinants of the predictive power of the NN\#1 model (with zSDBP 
as output variable), followed at a distance by hsCRP and the AIP index, and again at a distance by ANTIOX. Figure 4 shows that NOSTOX and body weight were the major determinants of SBP followed at a distance by hsCRP. Figure 5 shows that NOSTOX and BMI were the major determinants of the predictive power of the NN model with DBP as output variable.

\section{Discussion}

The first major finding of this study is that the blood pressure measurements were not significantly different between patients with mood disorders (MDD or BP1 and BP2) and healthy controls. These findings contrast with our a priori hypothesis. Shinn et al. (2001) found no significant relationships between depression and the development of hypertension over a four-year time frame (Shinn et al., 2001). In a study of 2992 normotensive subjects (25 to 64 years) who were followed for 6 to 7 years, high scores of depressive symptoms doubled the risk for hypertension (Scalco et al., 2005). A meta-analysis showed that individuals experiencing depression are at high risk for developing hypertension, as well as being predisposed to stroke and ischemic heart disease (Rubio-Guerra et al., 2013). In contrast, Licht et al (2009) found an association between depression and decreased blood pressure, suggesting that the association between depression and CVD may not be attributed to effects of hypertension (Licht et al., 2009). Importantly, although hypertension and MDD are not associated, they can interact to alter grey matter volumes in areas implicated in the regulation of emotional and autonomic functions (Meurs et al., 2015).

The second major finding of this study is that a) NOSTOX was an important predictor of increased blood pressure; and b) LOOH and AOPP were the most significant predictors of the 
variance in the blood pressure data followed by increased SOD. Interestingly, the composite score combining the effects of SOD $+\mathrm{LOOH}+\mathrm{AOPP}+\mathrm{NOx}$ was a much better predictor than any other biomarker separately (including MDA) or other combinations of the biomarkers. This suggests that the pathway from superoxide and NO production to lipid peroxidation and chlorinative stress with increased production of AOPP may in part underpin the pathophysiology of hypertension. We will now discuss the impact of those O\&NS factors on blood pressure and hypertension.

Ceriello (2008) showed that higher production of hydrogen peroxide may be observed in treated and untreated hypertensive subjects relative to normotensive subjects, with a significant correlation between hydrogen peroxide levels and systolic blood pressure. In addition, both malignant and nonmalignant hypertensive subjects have higher LOOH levels relative to control subjects (Ceriello, 2008). Furthermore, Niroumand et al. (2015) demonstrated that lipid peroxidation plays a key role in atherosclerosis. Hydroperoxides have toxic effects on cells both directly and indirectly through the formation of highly toxic hydroxyl radicals (Niroumand et al., 2015). Peroxidation of lipids produces highly reactive aldehydes, including MDA, which are highly associated with hypertension (Ahmad et al., 2013; Pawluk et al., 2017; Tiwari et al., 2013). Significantly higher values of LOOH and thiobarbituric acid-reactive substances (TBARS) in red blood cells as well as in serum and decreased erythrocyte antioxidant enzyme activities have been reported in patients with elevated blood pressure (Niroumand et al., 2015). Nevertheless, in the present study we observed that MDA, in contrast to LOOH and AOPP, was not associated with increased hypertension. Interestingly, Cracowski et al. (2002) found that in never-treated mild-tomoderate hypertension, lipid peroxidation was not increased, suggesting that this process may not be critical in the early stages and is more important in severe hypertension (Cracowski et al., 2002). 
Increased AOPP levels were established in patients with hypertensive nephropathy (Conti et al., 2019) whilst levels of modified AOPP were also increased in peritoneal dialysis patients (Xu et al., 2015). Nevertheless, no significant alterations in AOPP levels were established in peritoneal dialysis patients with and without hypertension (Demirci et al., 2011). AOPP measures increased levels of oxidized proteins, such as albumin and fibrinogen, and oxidized fibrinogen is a key molecule responsible for the AOPP reaction in human plasma (Selmeci et al., 2006; Xu et al., 2015). AOPPs are also pro-inflammatory and pro-oxidative compounds that accumulate in aging patients with diabetes and play a major role in increasing the prevalence of endothelial dysfunction and subsequent cardiovascular disease (Tiwari et al., 2013).

Gómez-Marcos et al. (2016) reported an association between serum SOD levels and parameters of vascular function in hypertensive and diabetic patients, indicating that oxidative stress significantly affects blood pressure (Gómez-Marcos et al., 2016) SOD catalyzes the partition of superoxide radicals into oxygen and hydrogen peroxides, which are further degraded into $\mathrm{H}_{2} \mathrm{O}$ by catalase. SOD is a major protective antioxidant enzyme against the damaging effects of increased superoxide levels and additionally protects against peroxynitrite formation (Fukai and Ushio-Fukai, 2011). Nevertheless, SOD activity is accompanied by increased formation of hydrogen peroxides, which can generate other ROS, including the very reactive hydroxyl or metalassociated radicals (Maes et al., 2018). Moreover, oxidative stress and inflammatory triggers may enhance SOD activity as well as its de novo synthesis especially in the early stages of an injury (Terrazzano et al., 2014). In mood disorders, increased SOD indicates a compensatory mechanism to neutralize increased ROS production (Maes et al., 2019a). Alterations in redox-related intracellular signaling (including mitogen-activated protein kinases and transcription factors) may 
lead to endothelial dysfunction, increased contraction, and structural re-modeling, causing increased peripheral resistance and elevated blood pressure (Xu et al., 2015).

Increased NOx levels indicate increased production of NO by endothelial cells and activated nitration and nitroslylation processes (Roomruangwong et al., 2017), which are key components of mood disorders (Maes et al., 2019b, 2011a, 2011b). In animal models, increased nitrosylation is a critical mechanism leading to vascular dysfunction and hypertension (Choi et al., 2011). Moreover, increased nitration and nitrosylation may be accompanied by functional NO deficiency (Roomruangwong et al., 2017) while the latter phenomenon is associated with hypertension (Vaziri et al., 2002) and enhanced atherosclerosis (Schulz et al., 2011). Finally, the half-life of NO and its biological activity is decisively determined by ROS such as superoxide anions, which rapidly bind to NO to form the highly reactive intermediate ONOO (Schulz et al., 2011) which has implications for the vascular pathology in hypertension (Guzik et al., 2002).

Not only NOSTOX was significantly associated with the increased blood pressure but also hsCRP. Numerous clinical trials reported that hypertensive patients, both males and females of varying ages, have increased plasma CRP levels (Tran et al., 2009; Xu et al., 2008). Prehypertensive patients generally have higher plasma CRP levels than normotensive patients, and higher baseline CRP levels are reportedly associated with a higher risk of developing overt hypertension, consistent with the concept that systemic low-grade inflammation may precede hypertension (Dauphinot et al., 2009). Low-grade inflammation defined as a 2- to 3-fold increase in plasma levels of pro-inflammatory cytokines, which stimulate the production of CRP, are frequently reported in hypertension (Dinh et al., 2014; Tkacova, 2010). 
In addition to the role of nitro-oxidative stress and CRP, we observed that also weight or BMI contribute to increased blood pressure. There is a significantly higher risk for elevated BP and prehypertension in people with high BMI (Hossain et al., 2019; Nafiu et al., 2014). Li et al. (2019) showed the importance of the interactions of different anthropometric indicators of obesity in assessing the risk of hypertension (Li et al., 2019). Obesity can increase hypertension through multiple mechanisms, including activation of the sympathetic nervous system, insulin resistance and sodium retention (Crump et al., 2016; Li et al., 2019).

We also found that 3 biomarkers associated with increased body weight or BMI are associated with increased blood pressure, namely increased atherogenicity (as measured using AIP or Castelli 1 indices), insulin resistance (as assessed using HOMA2IR index) and subclinical hypothyroidism (as assessed with increased TSH values). The AIP, an index of increased atherogenicity, was not significantly associated with hypertension (Niroumand et al., 2015). Nevertheless, there is evidence of a bidirectional relationship between hypertension and endothelial dysfunction, which is in part associated with increased atherogenicity indexes (Shimizu et al., 2017). Insulin resistance is associated with increased risk to develop hypertension (Ärnlöv et al., 2005), especially in nonobese persons and in analyses not accounting for obesity (Lytsy et al., 2014). Reaven et al. (2011) reported that patients with essential hypertension are insulin-resistant and that the latter process predicts the development of essential hypertension (Reaven, 2011). The long-term influences of insulin resistance may result in vascular hypertrophy and remodeling and renal effects (Ärnlöv et al., 2005). TSH is another biomarker that may be associated with an elevated blood pressure (Alderman, 2011). Thyroid hormone metabolism may impact hypertension via several mechanisms including effects on peripheral arteries, increased 
arterial stiffness, increased systemic vascular resistance, lowered cardiac output, and gene expression (Berta et al., 2019).

The third major finding of this study is that while there were no significant differences in blood pressure assessments between patients with mood disorders and controls, the association between both factors may differ between these groups. In controls, body weight and the Castelli risk index 1 were the best predictors of increased blood pressure, whereas in mood disorders NOSTOX and body weight were the most important determinants. By inference, the nitrooxidative stress toxicity associated with mood disorders (Maes et al., 2019a, 2018, 2011a) may underpin increments in systolic and diastolic blood pressure measurements in those patients.

This study has some limitations that must be considered in the interpretation of the results. First, this is a cross-sectional and correlational study and, therefore, we cannot draw firm conclusions on causal associations. Second, it would have been more interesting if we had also measured indices of endothelium dysfunction including carotid intima media thickness and other biomarkers associated with hypertension including adhesion molecules. Third, some participants used antihypertensive drugs, which could interfere with the results. However, our study showed that the effects of NOSTOX and immune-inflammatory biomarkers on BP were independent of the use of antihypertensives, and that the latter was positively associated with an increased BP reflecting the increased use of these drugs in cases with hypertension. Moreover, Levi-Marpillat et al (2014) showed that antihypertensive drugs may have different effects on short-term BP variability independently from the effects of major confounders such as BP level, age, gender, heart rate, etc (Levi-Marpillat et al., 2014). 
25

In conclusion, our results suggest that blood pressure in mood disorder patients is highly predicted by increased lipid peroxidation, protein oxidation, body weight or BMI, HOMA2IR, hsCRP, AIP, and basal TSH values. These biomarkers may cause hypertension through different mechanisms including O\&NS, immune-inflammatory processes, hypothalamus-pituitary-thyroid axis dysregulation, increased atherogenicity and insulin resistance. Although the blood pressure measurements were not significantly different between patients with mood disorders and controls, blood pressure was differentially modulated in both groups with a greater impact of nitro-oxidative stress in patients with mood disorders than in controls.

Funding

This study was supported by Health Sciences Postgraduate Program at Londrina State University, Parana, Brazil (UEL), and Ministry for Science and Technology of Brazil (CNPq). CNPq number 470344/2013-0. MM was supported by a CNPq - PVE fellowship and the Health Sciences Graduate Program fellowship, State University of Londrina.

Acknowledgements

The authors wish to thank the Centre of Approach and Treatment for Smokers, Psychiatric Unit at UEL, Clinical Laboratory of the University Hospital and Laboratory of Research and Graduate College Hospital (LPG), Brazil.

Authorships 
All authors contributed to the writing up of the paper. The work was designed by SOVN, MM, DSB, EGM and HOV. Data were collected by KLB, JBM, SOVN and HOV. Laboratory analyses were conducted by KLB, CFC, EGM and DSB. Statistics were performed by MM. All authors revised and approved the final draft.

\section{References}

Ahmad, A., Singhal, U., Hossain, M.M., Islam, N., Rizvi, I., 2013. The role of the endogenous antioxidant enzymes and malondialdehyde in essential hypertension. J. Clin. Diagnostic Res. 7, 987-990. doi:10.7860/JCDR/2013/5829.3091

Alberti, K.G.M., Zimmet, P., Shaw, J., IDF Epidemiology Task Force Consensus Group, 2005. The metabolic syndrome — a new worldwide definition. Lancet 366, 1059-1062. doi:10.1016/S0140-6736(05)67402-8

Alderman, M.H., 2011. TSH Is Associated With Blood Pressure in Hypertension- Regardless of Etiology and The DASH Diet and Nocturnal Dipping: Does Ethnicity Matter? Am. J.

Hypertens. 24, 1263-1263. doi:10.1038/ajh.2011.205

American Psychiatric Association, 2000. Diagnostic and Statistical Manual of Mental Disorders, Fourth Edition, Text Revision (DSM-IV-TR), Text. doi:10.1176/appi.books.9780890423349

Ärnlöv, J., Pencina, M.J., Nam, B.H., Meigs, J.B., Fox, C.S., Levy, D., D’Agostino, R.B., Vasan, R.S., 2005. Relations of insulin sensitivity to longitudinal blood pressure tracking: Variations with baseline age, body mass index, and blood pressure. Circulation 112, 17191727. doi:10.1161/CIRCULATIONAHA.105.535039 
Baronaite-Dudoniene, K., Sakalyte, G., Urbonaite, L., Karaliute, R., 2015. ANXIETY AND DEPRESSION IN PATIENTS WITH ARTERIAL HYPERTENSION. J. Hypertens. 33, 2015. doi:doi: 10.1097/01.hjh.0000468624.98938.48

Bastos, A.S., Loureiro, A.P.D.M., de Oliveira, T.F., Corbi, S.C.T., Caminaga, R.M.S., Júnior, C.R., Orrico, S.R.P., 2012. Quantitation of malondialdehyde in gingival crevicular fluid by a high-performance liquid chromatography-based method. Anal. Biochem. 423, 141-146. doi:10.1016/j.ab.2012.01.016

Berk, M., Kapczinski, F., Andreazza, A.C., Dean, O.M., Giorlando, F., Maes, M., Yücel, M., Gama, C.S., Dodd, S., Dean, B., Magalhães, P.V.S., Amminger, P., McGorry, P., Malhi, G.S., 2011. Pathways underlying neuroprogression in bipolar disorder: focus on inflammation, oxidative stress and neurotrophic factors. Neurosci. Biobehav. Rev. 35, 80417. doi:10.1016/j.neubiorev.2010.10.001

Berta, E., Lengyel, I., Halmi, S., Zrínyi, M., Erdei, A., Harangi, M., Páll, D., Nagy, E. V., Bodor, M., 2019. Hypertension in thyroid disorders. Front. Endocrinol. (Lausanne). 10, 1-11. doi:10.3389/fendo.2019.00482

Boal, A.H., Smith, D.J., McCallum, L., Muir, S., Touyz, R.M., Dominiczak, A.F., Padmanabhan, S., 2016. Monotherapy with major antihypertensive drug classes and risk of hospital admissions for mood disorders. Hypertension 68, 1132-1138. doi:10.1161/HYPERTENSIONAHA.116.08188

Bonifácio, L.K., Sabbatini Barbosa, D., Gastaldello Moreira, E., de Farias, C.C., Higachi, L., Camargo, A.E.I., Favaro Soares, J., Odebrecht Vargas, H., Nunes, S.O.V., Berk, M., Dodd, S., Maes, M., 2017. Indices of insulin resistance and glucotoxicity are not associated with 
bipolar disorder or major depressive disorder, but are differently associated with inflammatory, oxidative and nitrosative biomarkers. J. Affect. Disord. 222. doi:10.1016/j.jad.2017.07.010

Calkin, C. V., Ruzickova, M., Uher, R., Hajek, T., Slaney, C.M., Garnham, J.S., O’Donovan, M.C., Alda, M., 2015. Insulin resistance and outcome in bipolar disorder. Br. J. Psychiatry 206, 52-57. doi:10.1192/bjp.bp.114.152850

Carrizzo, A., Puca, A., Damato, A., Marino, M., Franco, E., Pompeo, F., Traficante, A., Civitillo, F., Santini, L., Trimarco, V., Vecchione, C., 2013. Resveratrol improves vascular function in patients with hypertension and dyslipidemia by modulating NO metabolism. Hypertension 62, 359-366. doi:10.1161/HYPERTENSIONAHA.111.01009

Ceriello, A., 2008. Possible role of oxidative stress in the pathogenesis of hypertension. Diabetes Care 31 Suppl 2. doi:10.2337/dc08-s245

Choi, H., Allahdadi, K.J., Tostes, R.C., Webb, R.C., 2011. Augmented S-nitrosylation contributes to impaired relaxation in angiotensin II hypertensive mouse aorta: Role of thioredoxin reductase. J. Hypertens. 29, 2359-2368. doi:10.1097/HJH.0b013e32834d2554

Conti, G., Caccamo, D., Siligato, R., Gembillo, G., Satta, E., Pazzano, D., Carucci, N., Carella, A., Del Campo, G., Salvo, A., Santoro, D., 2019. Association of higher advanced oxidation protein products (AOPPs) levels in patients with diabetic and hypertensive nephropathy. Med. 55. doi:10.3390/medicina55100675

Cracowski, J.L., Durand, T., Bessard, G., 2002. Isoprostanes as a biomarker of lipid peroxidation in humans: Physiology, pharmacology and clinical implications. Trends Pharmacol. Sci. 23, 360-366. doi:10.1016/S0165-6147(02)02053-9 
Crump, C., Sundquist, J., Winkleby, M.A., Sundquist, K., 2016. Interactive effects of physical fitness and body mass index on the risk of hypertension. JAMA Intern. Med. 176, 210-216. doi:10.1001/jamainternmed.2015.7444

Dauphinot, V., Roche, F., Kossovsky, M.P., Schott, A.M., Pichot, V., Gaspoz, J.M., Gossee, P., Barthelemy, J.C., 2009. C-reactive protein implications in new-onset hypertension in a healthy population initially aged 65 years: the Proof study. J. Hypertens. 27, 736-743. doi:10.1097/HJH.0b013e328326f801

de Melo, L.G.P., Nunes, S.O.V., Anderson, G., Vargas, H.O., Barbosa, D.S., Galecki, P., Carvalho, A.F., Maes, M., 2017. Shared metabolic and immune-inflammatory, oxidative and nitrosative stress pathways in the metabolic syndrome and mood disorders. Prog. Neuro-Psychopharmacology Biol. Psychiatry 78, 34-50. doi:10.1016/j.pnpbp.2017.04.027

Del-Ben, C.M., Antônio, J., Vilela, A., Alexandre, J., Crippa, D.S., Eduardo, J., Hallak, C., Labate, C.M., 2001. Confiabilidade da “Entrevista Clínica Estruturada para o DSM-IV Versão Clínica " traduzida para o português Reliability of the Structured Clinical Interview for DSM-IV - Clinical Version translated into Portuguese. Rev. Bras. Psiquiatr. 23, 7-10. doi:10.1590/S1516-44462001000300008

Demirci, Ş., Şekeroğlu, M.R., Noyan, T., Köçeroğlu, R., Soyoral, Y.U., Dülger, H., Erkoç, R., 2011. The importance of oxidative stress in patients with chronic renal failure whose hypertension is treated with peritoneal dialysis. Cell Biochem. Funct. 29, 249-254. doi:10.1002/cbf.1744

Dinh, Q.N., Drummond, G.R., Sobey, C.G., Chrissobolis, S., 2014. Roles of inflammation, oxidative stress, and vascular dysfunction in hypertension. Biomed Res. Int. 2014. 
30

doi: $10.1155 / 2014 / 406960$

Flecha, B.G., Llesuy, S., Boveris, A., 1991. Hydroperoxide-initiated chemiluminescence: An assay for oxidative stress in biopsies of heart, liver, and muscle. Free Radic. Biol. Med. 93100. doi:10.1016/0891-5849(91)90002-K

Fugger, G., Dold, M., Bartova, L., Kautzky, A., Souery, D., Mendlewicz, J., Serretti, A., Zohar, J., Montgomery, S., Frey, R., Kasper, S., 2019. Major Depression and Comorbid Diabetes Findings from the European Group for the Study of Resistant Depression. Prog. NeuroPsychopharmacology Biol. Psychiatry 94, 109638. doi:10.1016/j.pnpbp.2019.109638

Fukai, T., Ushio-Fukai, M., 2011. Superoxide dismutases: Role in redox signaling, vascular function, and diseases. Antioxidants Redox Signal. 15, 1583-1606. doi:10.1089/ars.2011.3999

Goldstein, B.I., Carnethon, M.R., Matthews, K.A., Mcintyre, R.S., Miller, G.E., Raghuveer, G., Stoney, C.M., Wasiak, H., Mccrindle, B.W., 2015. Major Depressive Disorder and Bipolar Disorder and Early Cardiovascular Disease. Circulation 131, 965-987. doi:10.1161/CIR.0000000000000229

Gómez-Marcos, M.A., Blázquez-Medela, A.M., Gamella-Pozuelo, L., Recio-Rodriguez, J.I., García-Ortiz, L., Martínez-Salgado, C., 2016. Serum Superoxide Dismutase Is Associated with Vascular Structure and Function in Hypertensive and Diabetic Patients. Oxid. Med. Cell. Longev. 2016. doi:10.1155/2016/9124676

Gupta, A., Chaudhary, N., Gupta, K.K., Verma, S.L., Singh, G., 2019. Association of insulin resistance and blood pressure in newly diagnosed patients of essential hypertension: A cross-sectional study. Journal, Indian Acad. Clin. Med. 20, 170-174. 
Guzik, T.J., West, N.E.J., Pillai, R., Taggart, D.P., Channon, K.M., 2002. Nitric oxide modulates superoxide release and peroxynitrite formation in human blood vessels. Hypertension 39, 1088-1094. doi:10.1161/01.HYP.0000018041.48432.B5

Hanasand, M., Omdal, R., Norheim, K.B., Gøransson, L.G., Brede, C., Jonsson, G., 2012. Improved detection of advanced oxidation protein products in plasma. Clin. Chim. Acta 413, 901-906. doi:10.1016/j.cca.2012.01.038

Hildrum, B., Mykletun, A., Stordal, E., Bjelland, I., Dahl, A.A., Holmen, J., 2007. Association of low blood pressure with anxiety and depression: The Nord-Trøndelag Health Study. J. Epidemiol. Community Health 61, 53-58. doi:10.1136/jech.2005.044966

Hossain, F.B., Adhikary, G., Chowdhury, A.B., Shawon, M.S.R., 2019. Association between body mass index (BMI) and hypertension in south Asian population: evidence from nationally-representative surveys. Clin. Hypertens. 25, 1-9. doi:10.1186/s40885-019-01348

Kan, C., Silva, N., Golden, S.H., Rajala, U., Timonen, M., Stahl, D., Ismail, K., 2013. A systematic review and meta-analysis of the association between depression and insulin resistance. Diabetes Care 36, 480-489. doi:10.2337/dc12-1442

Kearney, P.M., Whelton, M., Reynolds, K., Muntner, P., Whelton, P.K., He, J., 2005. Global burden of hypertension: analysis of worldwide data. Lancet (London, England) 365, 21723. doi:10.1016/S0140-6736(05)17741-1

Levi-Marpillat, N., MacQuin-Mavier, I., Tropeano, A.I., Parati, G., Maison, P., 2014. Antihypertensive drug classes have different effects on short-term blood pressure variability in essential hypertension. Hypertens. Res. 37, 585-590. doi:10.1038/hr.2014.33 
Li, A., Peng, Q., Shao, Y., Fang, X., Zhang, Y., 2019. The effect of body mass index and its interaction with family history on hypertension: a case-control study. Clin. Hypertens. 25, 1-8. doi:10.1186/s40885-019-0111-2

Licht, C.M.M., Geus, E.J.C.D., Seldenrijk, A., Hout, H.P.J.V., Zitman, F.G., Dyck, R. Van, Penninx, B.W.J.H., 2009. Depression is associated with decreased blood pressure, but antidepressant use increases the risk for hypertension. Hypertension 53, 631-638. doi:10.1161/HYPERTENSIONAHA.108.126698

Liu, T., Zhong, S., Liao, X., Chen, J., He, T., Lai, S., Jia, Y., 2015. A meta-analysis of oxidative stress markers in depression. PLoS One 10, 1-17. doi:10.1371/journal.pone.0138904

Lytsy, P., Ingelsson, E., Lind, L., Ärnlöv, J., Sundström, J., 2014. Interplay of overweight and insulin resistance on hypertension development. J. Hypertens. 32, 834-839. doi:10.1097/HJH.0000000000000081

Maes, M., Bonifacio, K.L., Morelli, N.R., Vargas, H.O., Moreira, E.G., St. Stoyanov, D., Barbosa, D.S., Carvalho, A.F., Nunes, S.O.V., 2018. Generalized Anxiety Disorder (GAD) and Comorbid Major Depression with GAD Are Characterized by Enhanced Nitrooxidative Stress, Increased Lipid Peroxidation, and Lowered Lipid-Associated Antioxidant Defenses. Neurotox. Res. 34, 489-51. doi:10.1007/s12640-018-9906-2

Maes, M., Bonifacio, K.L., Vargas, H.O., Barbosa, D.S., Carvalho, A., Nunes, S., 2019a. Major differences in neuro-oxidative and neuro-nitrosative stress pathways between major depressive disorder and types I and II bipolar disorders. Mol. Neurobiol. 56, 141-156. doi:doi.org/10.1007/s12035-018-1051-7

Maes, M., Galecki, P., Chang, Y.S., Berk, M., 2011a. A review on the oxidative and nitrosative 
stress (O\&NS) pathways in major depression and their possible contribution to the (neuro)degenerative processes in that illness. Prog. Neuro-Psychopharmacology Biol. Psychiatry 35, 676-692. doi:10.1016/j.pnpbp.2010.05.004

Maes, M., Ruckoanich, P., Chang, Y.S., Mahanonda, N., Berk, M., 2011b. Multiple aberrations in shared inflammatory and oxidative \& nitrosative stress (IO\&NS) pathways explain the co-association of depression and cardiovascular disorder (CVD), and the increased risk for CVD and due mortality in depressed patients. Prog. Neuro-Psychopharmacology Biol. Psychiatry 35, 769-783. doi:10.1016/j.pnpbp.2010.06.008

Maes, M., Simeonova, D., Stoyanov, D., Leunis, J.C., 2019b. Upregulation of the nitrosylome in bipolar disorder type 1 (BP1) and major depression, but not BP2: Increased IgM antibodies to nitrosylated conjugates are associated with indicants of leaky gut. Nitric Oxide - Biol. Chem. 91, 67-76. doi:10.1016/j.niox.2019.07.003

Marklund, S., Marklund, G., 1974. Involvement of the superoxide anion radical in the autoxidation of pyrogallol and a convenient assay for superoxide dismutase. Eur. J. Biochem. 47, 469-474. doi:10.1111/j.1432-1033.1974.tb03714.x

Meurs, M., Groenewold, N.A., Roest, A.M., Van Der Wee, N.J.A., Veltman, D.J., Van Tol, M.J., De Jonge, P., 2015. The associations of depression and hypertension with brain volumes: Independent or interactive? NeuroImage Clin. 8, 79-86. doi:10.1016/j.nicl.2015.03.020

Montezano, A.C., Dulak-Lis, M., Tsiropoulou, S., Harvey, A., Briones, A.M., Touyz, R.M., 2015. Oxidative stress and human hypertension: Vascular mechanisms, biomarkers, and novel therapies. Can. J. Cardiol. 31, 631-641. doi:10.1016/j.cjca.2015.02.008

Montezano, A.C., Touyz, R.M., 2014. Reactive oxygen species, vascular noxs, and hypertension: 
Focus on translational and clinical research. Antioxidants Redox Signal. 20, 164-182. doi:10.1089/ars.2013.5302

Montezano, A.C., Touyz, R.M., 2012. Molecular Mechanisms of Hypertension-Reactive Oxygen Species and Antioxidants: A Basic Science Update for the Clinician. Can. J. Cardiol. 28, 288-295. doi:10.1016/j.cjca.2012.01.017

Moreno, R., Moreno, D., 1998. Hamilton and Montgomery \&amp; Ásberg depression rating scales. Rev. Psiquiatr. Clin. 25, 262-272.

Nafiu, O.O., Zepeda, A., Curcio, C., Prasad, Y., 2014. Association of neck circumference and obesity status with elevated blood pressure in children. J. Hum. Hypertens. 28, 263-268. doi:10.1038/jhh.2013.93

Navarro-Gonzálvez, J. a, García-Benayas, C., Arenas, J., 1998. Semiautomated measurement of nitrate in biological fluids. Clin. Chem. 44, 679-81. doi:10.1093/clinchem/44.3.679

Niroumand, S., Khajedaluee, M., Khadem-Rezaiyan, M., Abrishami, M., Juya, M., Khodaee, G., Dadgarmoghaddam, M., 2015. Atherogenic Index of Plasma (AIP): A marker of cardiovascular disease. Med. J. Islam. Repub. Iran 29, 627-635. doi:eCollection 2015

Ormazabal, V., Nair, S., Elfeky, O., Aguayo, C., Salomon, C., Zuñiga, F.A., 2018. Association between insulin resistance and the development of cardiovascular disease. Cardiovasc.

Diabetol. 17, 1-14. doi:10.1186/s12933-018-0762-4

Ösby, U., Brandt, L., Correia, N., Ekbom, A., Sparén, P., 2001. Excess mortality in bipolar and unipolar disorder in Sweden. Arch. Gen. Psychiatry 58, 844-850. doi:10.1001/archpsyc.58.9.844

Panis, C., Herrera, A.C.S.A., Victorino, V.J., Campos, F.C., Freitas, L.F., De Rossi, T., Colado 
Simão, A.N., Cecchini, A.L., Cecchini, R., 2012. Oxidative stress and hematological profiles of advanced breast cancer patients subjected to paclitaxel or doxorubicin chemotherapy. Breast Cancer Res. Treat. 133, 89-97. doi:10.1007/s10549-011-1693-x

Pawluk, H., Pawluk, R., Robaczewska, J., Kędziora-Kornatowska, K., Kędziora, J., 2017. Biomarkers of antioxidant status and lipid peroxidation in elderly patients with hypertension. Redox Rep. 22, 542-546. doi:10.1080/13510002.2017.1372072

Reaven, G.M., 2011. Relationships Among Insulin Resistance, Type 2 Diabetes, Essential Hypertension, and Cardiovascular Disease: Similarities and Differences. J. Clin. Hypertens. 13, 238-243. doi:10.1111/j.1751-7176.2011.00439.x

Richter, R.J., Jarvik, G.P., Furlong, C.E., 2008. Determination of paraoxonase 1 status without the use of toxic organophosphate substrates. Circ. Cardiovasc. Genet. 1, 147-152. doi:10.1161/CIRCGENETICS.108.811638

Roomruangwong, C., Kanchanatawan, B., Sirivichayakul, S., Anderson, G., Carvalho, A.F., Duleu, S., Geffard, M., Maes, M., 2017. IgM-mediated autoimmune responses to oxidative specific epitopes, but not nitrosylated adducts, are significantly decreased in pregnancy: association with bacterial translocation, perinatal and lifetime major depression and the tryptophan catabolite (TRYC. Metab. Brain Dis. 32, 1571-1583. doi:10.1007/s11011-0170040-2

Rubio-Guerra, A.F., Rodriguez-Lopez, L., Vargas-Ayala, G., Huerta-Ramirez, S., Serna, D.C., Lozano-Nuevo, J.J., 2013. Depression increases the risk for uncontrolled hypertension. Exp. Clin. Cardiol. 18, 10-12.

Scalco, A.Z., Scalco, M.Z., Azul, J.B.S., Lotufo Neto, F., 2005. Hypertension and depression. 
Clinics (Sao Paulo). 60, 241-250. doi:10.1590/S1807-59322005000300010

Schulz, E., Gori, T., Münzel, T., 2011. Oxidative stress and endothelial dysfunction in hypertension. Hypertens. Res. 34, 665-673. doi:10.1038/hr.2011.39

Selmeci, L., Székely, M., Soós, P., Seres, L., Klinga, N., Geiger, A., Acsády, G., 2006. Human blood plasma advanced oxidation protein products (AOPP) correlates with fibrinogen levels. Free Radic. Res. 40, 952-958. doi:10.1080/10715760600818789

Shen, Q., Bergquist-Beringer, S., 2013. Relationship between major depression and insulin resistance: Does it vary by gender or race/ethnicity among young adults aged 20-39 years? J. Diabetes 5, 471-481. doi:10.1111/1753-0407.12044

Shimizu, Y., Sato, S., Koyamatsu, J., Yamanashi, H., Nagayoshi, M., Kadota, K., Kawashiri, S.Y., Inoue, K., Nagata, Y., Maeda, T., 2017. Platelets and circulating CD34-positive cells as an indicator of the activity of the vicious cycle between hypertension and endothelial dysfunction in elderly Japanese men. Atherosclerosis 259, 26-31. doi:10.1016/j.atherosclerosis.2017.02.016

Shinn, E.H., Poston, W.S.C., Kimball, K.T., St. Jeor, S.T., Foreyt, J.P., 2001. Blood pressure and symptoms of depression and anxiety: A prospective study. Am. J. Hypertens. 14, 660-664. doi:10.1016/S0895-7061(01)01304-8

Sugiura, T., Dohi, Y., Takase, H., Yamashita, S., Tanaka, S., Kimura, G., 2011. Increased reactive oxygen metabolites is associated with cardiovascular risk factors and vascular endothelial damage in middle-aged Japanese subjects. Vasc. Health Risk Manag. 7, 475482. doi:10.2147/VHRM.S23097

Terrazzano, G., Rubino, V., Damiano, S., Sasso, A., Petrozziello, T., Ucci, V., Palatucci, A.T., 
Giovazzino, A., Santillo, M., De Felice, B., Garbi, C., Mondola, P., Ruggiero, G., 2014. T cell activation induces $\mathrm{CuZn}$ superoxide dismutase (SOD)-1 intracellular re-localization, production and secretion. Biochim. Biophys. Acta - Mol. Cell Res. 1843, 265-274. doi:10.1016/j.bbamcr.2013.10.020

Tiwari, B.K., Pandey, K.B., Abidi, A.B., Rizvi, S.I., 2013. Markers of Oxidative Stress during Diabetes Mellitus. J. Biomarkers 2013, 1-8. doi:10.1155/2013/378790

Tkacova, R., 2010. Systemic inflammation in chronic obstructive pulmonary disease: May adipose tissue play a role? Review of the literature and future perspectives. Mediators Inflamm. 2010, 11. doi:10.1155/2010/585989

Tran, L.T., Yuen, V.G., McNeill, J.H., 2009. The fructose-fed rat: A review on the mechanisms of fructose-induced insulin resistance and hypertension. Mol. Cell. Biochem. 332, 145-159. doi:10.1007/s11010-009-0184-4

Vaziri, N.D., Ni, Z., Oveisi, F., Liang, K., Pandian, R., 2002. Enhanced nitric oxide inactivation and protein nitration by reactive oxygen species in renal insufficiency. Hypertension 39, 135-141. doi:10.1161/hy0102.100540

Ward, N.C., Hodgson, J.M., Puddey, I.B., Mori, T.A., Beilin, L.J., Croft, K.D., 2004. Oxidative stress in human hypertension: Association with antihypertensive treatment, gender, nutrition, and lifestyle. Free Radic. Biol. Med. 36, 226-232.

doi:10.1016/j.freeradbiomed.2003.10.021

Xu, H., Cabezas-Rodriguez, I., Qureshi, A.R., Heimburger, O., Barany, P., Snaedal, S., Anderstam, B., Helin, A.C.B., Carrero, J.J., Stenvinkel, P., Lindholm, B., 2015. Increased levels of modified advanced oxidation protein products are associated with central and 
peripheral blood pressure in peritoneal dialysis patients. Perit. Dial. Int. 35, 460-470. doi:10.3747/pdi.2013.00064

Xu, T., Ju, Z., Tong, W., Hu, W., Liu, Y., Zhao, L., Zhang, Y., 2008. Relationship of C-reactive protein with hypertension and interactions between increased C-reactive protein and other risk factors on hypertension in Mongolian people, China. Circ. J. 72, 1324-1328. doi:10.1253/circj.72.1324

Yu, M., Zhang, X., Lu, F., Fang, L., 2015. Depression and Risk for Diabetes: A Meta-Analysis. Can. J. Diabetes 39, 266-272. doi:10.1016/j.jcjd.2014.11.006 
Table 1. Socio-demographic, clinical and biomarker data of the study population classified according to the sum of the $z$ score obtained for their systolic blood pressure and for their diastolic blood pressure into lower (i.e., < median) and higher (i.e., > median) blood pressure.

\begin{tabular}{|c|c|c|c|c|c|}
\hline \multirow[t]{2}{*}{ Variables } & \multicolumn{2}{|c|}{ z systolic + z diastolic BP } & \multirow[t]{2}{*}{$F / X^{2}$} & \multirow[t]{2}{*}{$\mathrm{Df}$} & \multirow[t]{2}{*}{$P$} \\
\hline & $<q 75$ values & $\geq q 75$ values & & & \\
\hline Sex (Female/Male) & $81 / 19$ & $41 / 21$ & 4.55 & 1 & 0.033 \\
\hline Age (years) & $42.3(11.5)$ & $43.0(10.6)$ & 0.15 & $1 / 160$ & 0.700 \\
\hline Education (years) & $11.4(5.4)$ & $11.1(4.9)$ & 0.21 & $1 / 159$ & 0.651 \\
\hline Income (Brazilian minimum salaries) & $3.33(1.4)$ & $3.37(1.4)$ & 0.04 & $1 / 158$ & 0.846 \\
\hline Systolic pressure (mm Hg) & $109.2(9.5)$ & $130.2(13.6)$ & 134.55 & $1 / 160$ & $<0.001$ \\
\hline Diastolic pressure (mm Hg) & $68.8(5.9)$ & $83.7(7.7)$ & 191.71 & $1 / 160$ & $<0.001$ \\
\hline Body weight (kg) & $66.9(13.3)$ & $77.3(14.9)$ & 21.26 & $1 / 160$ & $<0.001$ \\
\hline Waist circunference $(\mathrm{cm})$ & $89.0(12.5)$ & $98.0(12.1)$ & 17.63 & $1 / 143$ & $<0.001$ \\
\hline Body Mass Index $\left(\mathrm{kg} / \mathrm{m}^{2}\right)$ & $25.1(4.5)$ & $28.6(4.7)$ & 21.72 & $1 / 159$ & $<0.001$ \\
\hline Metabolic Syndrome (No/Yes) & $68 / 32$ & $30 / 32$ & 6.16 & 1 & 0.013 \\
\hline NOSTOX (z scores) & $-0.49(1.94)$ & $0.59(2.53)$ & 8.08 & $1 / 138$ & 0.005 \\
\hline ANTIOX (z scores) & $0.21(1.89)$ & $-0.44(1.83)$ & 4.00 & $1 / 138$ & 0.047 \\
\hline zTRY-zHDL (z scores) & $-0.30(1.72)$ & $+0.50(1.46)$ & 8.57 & $1 / 148$ & 0.004 \\
\hline zTC-zHDL (z scores) & $-0.24(1.33)$ & $+0.39(1.33)$ & 8.02 & $1 / 148$ & 0.005 \\
\hline $\mathrm{hsCRP}(\mathrm{mg} / \mathrm{L}) *$ & $3.18(4.00)$ & $5.50(7.17)$ & 7.99 & $1 / 148$ & 0.005 \\
\hline HOMA2IR & $1.06(0.54)$ & $1.48(1.09)$ & 10.06 & $1 / 143$ & 0.002 \\
\hline Basal TSH ( $\mu \mathrm{UI} / \mathrm{mL})$ & $1.98(1.17)$ & $2.97(4.26)$ & 4.72 & $1 / 145$ & 0.031 \\
\hline Diagnosis (HC/BP2/BP1/MDD) & $39 / 26 / 13 / 22$ & $27 / 12 / 8 / 15$ & 1.00 & 2 & 0.802 \\
\hline Hamilton Depression Rating Scale & $7.2(6.4)$ & $7.4(7.3)$ & 0.05 & $1 / 160$ & 0.816 \\
\hline Tobacco Use Disorder (No/Yes) & $39 / 61$ & $33 / 29$ & 3.14 & 1 & 0.077 \\
\hline Antidepressants (No/Yes) & $68 / 26$ & $41 / 18$ & 0.14 & 1 & 0.705 \\
\hline Antipsychotics (No/Yes) & $76 / 18$ & $50 / 9$ & 0.38 & 1 & 0.538 \\
\hline Lithium (No/Yes) & $84 / 9$ & $49 / 10$ & 1.75 & 1 & 0.186 \\
\hline Anticonvulsants (No/Yes) & $79 / 14$ & $47 / 12$ & 0.71 & 1 & 0.399 \\
\hline Statins (No/Yes) & $91 / 9$ & $53 / 9$ & 1.18 & 1 & 0278 \\
\hline Antihypertensives (No/Yes) & $80 / 12$ & $35 / 23$ & 14.08 & 1 & $<0.001$ \\
\hline
\end{tabular}


Continuous variables are shown as mean $( \pm S D)$ and were analyzed by ANOVA whereas nominal variables are shown as frequency and were analyzed by Chi-Square test. BP: blood pressure.

NOSTOX or zLOOH+AOPP+NOx+SOD: sum of z transformation of LOOH (lipid hydroperoxides), AOPP (advanced oxidation protein products), NOx (nitric oxide metabolites) and SOD (superoxide dismutase); ANTIOX or ZPON1+CAT+HDL-c: sum of z transformation of PON1 (paraoxonase 1 activity), CAT (catalase) and HDL;

zTRY-zHDL: reflects the atherogenic index of plasma computed as z triglycerides - z high-density-lipoprotein cholesterol; zTC-zHDL: reflects Castelli risk index 1 and is computed as z total cholesterol - zHDL.

hSCRP: highly sensitive C-reactive protein; HOMA2IR: homeostasis model assessment of insulin resistance; TSH: thyroid-stimulating hormone; HC: healthy controls; BD: bipolar disorder types BP1 and BP2; MDD: major depressive disorder.

*Processed in Ln transformation 


\section{1}

Table 2. Results of automatic stepwise multiple regression analyses with blood pressure (BP) as dependent variable.

\begin{tabular}{|c|c|c|c|c|c|c|c|c|}
\hline $\begin{array}{l}\text { Dependent } \\
\text { variable }\end{array}$ & Explanatory variables & $\beta$ & $\mathbf{t}$ & $\mathbf{P}$ & $\begin{array}{c}R^{2} \\
\text { (model) }\end{array}$ & $\mathbf{F}$ & df & $\mathbf{P}$ \\
\hline \multirow[t]{3}{*}{ \#1a. SBP } & Body weight & 0.225 & +2.61 & 0.010 & $28.3 \%$ & 16.04 & $3 / 122$ & $<0.001$ \\
\hline & NOSTOX & 0.339 & +4.34 & $<0.001$ & & & & \\
\hline & hsCRP & 0.225 & +2.64 & 0.009 & & & & \\
\hline \multirow[t]{4}{*}{ \#1b. SBP } & Body weight & 0.217 & +2.55 & 0.012 & $31.6 \%$ & 13.98 & $4 / 121$ & $<0.001$ \\
\hline & NOSTOX & 0.320 & +4.16 & $<0.001$ & & & & \\
\hline & Antihypertensives & 0.189 & +2.43 & 0.017 & & & & \\
\hline & hsCRP & 0.184 & 2.16 & 0.032 & & & & \\
\hline \multirow[t]{2}{*}{ \#2a. DBP } & BMI & 0.371 & +4.68 & $<0.001$ & $23.8 \%$ & 19.26 & $2 / 123$ & $<0.001$ \\
\hline & NOSTOX & 0.277 & +3.50 & 0.001 & & & & \\
\hline \multirow[t]{3}{*}{ \#2b. DBP } & $\mathrm{BMI}$ & 0.308 & +3.81 & $<0.001$ & $28.0 \%$ & 15.81 & $3 / 122$ & $<0.001$ \\
\hline & NOSTOX & 0.262 & +3.38 & 0.001 & & & & \\
\hline & Antihypertensive drugs & 0.214 & +2.65 & 0.009 & & & & \\
\hline \multirow[t]{2}{*}{ \#3 zSDBP } & BMI & 0.221 & +2.48 & 0.015 & $33.5 \%$ & 15.25 & $4 / 121$ & $<0.001$ \\
\hline & NOSTOX & 0.325 & +4.33 & $<0.001$ & & & & \\
\hline
\end{tabular}




\begin{tabular}{llll}
\hline Antihypertensive drugs & 0.194 & +2.48 & 0.014 \\
hsCRP & 0.179 & +2.05 & 0.043 \\
\hline
\end{tabular}

SBP and DBP: systolic and diastolic blood pressure, respectively; zSDBP: sum of the z transformation of systolic and diastolic blood pressures. BMI: body mass index; hSCRP: highly sensitive C-reactive protein (processed in Ln transformation)

$\mathrm{NOSTOX}$ or zLOOH+zAOPP+zNOx+zSOD: sum of z transformations of LOOH (lipid hydroperoxides) + z AOPP (advanced oxidation protein products) + z NOx (nitric oxide metabolites) + z SOD (superoxide dismutase). 
Table 3. Results of automatic stepwise binary logistic regression analyses with the group with increased blood pressure (see Table 1) as dependent variable.

\begin{tabular}{|c|c|c|c|c|c|c|c|c|}
\hline Dependent variables & $\begin{array}{l}\text { Significant explanatory } \\
\text { variables }\end{array}$ & B & SE & Wald & df & $\mathbf{p}$ & OR & $\mathrm{Cl}-95 \%$ \\
\hline $\begin{array}{l}\text { \#1. Model without anti- } \\
\text { hypertensives }\end{array}$ & hsCRP & 0.584 & 0.213 & 7.54 & 1 & 0.006 & 1.79 & $1.18-2.72$ \\
\hline \multirow{2}{*}{$\begin{array}{l}\text { \#2. Model with anti- } \\
\text { hypertensives }\end{array}$} & hsCRP & 0.470 & 0.222 & 4.47 & 1 & 0.035 & 1.60 & $1.04-2.47$ \\
\hline & Antihypertensives & 1.489 & 0.470 & 10.03 & 1 & 0.002 & 4.43 & $1.76-11.14$ \\
\hline
\end{tabular}

NOSTOX or zLOOH+ZAOPP+zNOx+zSOD: sum of z transformations of LOOH (lipid hydroperoxides) + z AOPP (advanced oxidation protein products) + z NOx (nitric oxide metabolites) + z SOD (superoxide dismutase).

hsCRP: highly sensitive C-reactive protein (processed in Ln transformation) 
Table 4. Results of multiple regression analysis with blood pressure variables as dependent variable.

\begin{tabular}{|c|c|c|c|c|c|c|c|c|}
\hline Dependent variable & Explanatory variables & $\beta$ & $\mathbf{t}$ & $p$ & $\mathrm{R}^{2}$ (model) & $\mathbf{F}$ & df & $p$ \\
\hline \#1. SBP & $\begin{array}{l}\text { NOSTOX } \\
\text { Antihypertensive drugs } \\
\text { zTRY-zHDL }\end{array}$ & $\begin{array}{l}0.296 \\
0.240 \\
0.197\end{array}$ & $\begin{array}{l}+3.67 \\
+3.02 \\
+2.41\end{array}$ & $\begin{array}{l}<0.001 \\
0.003 \\
0.017\end{array}$ & $24.3 \%$ & 13.30 & $3 / 124$ & $<0.001$ \\
\hline \#2. SBP & $\begin{array}{l}\text { NOSTOX } \\
\text { Antihypertensive drugs } \\
\text { Homa2IR }\end{array}$ & $\begin{array}{l}0.335 \\
0.214 \\
0.181\end{array}$ & $\begin{array}{r}+4.15 \\
+2.54 \\
+2.16\end{array}$ & $\begin{array}{l}<0.001 \\
<0.012 \\
0.032\end{array}$ & $22.1 \%$ & 11.38 & $3 / 120$ & $<0.001$ \\
\hline \#3. SBP & $\begin{array}{l}\text { NOSTOX } \\
\text { Antihypertensive drugs } \\
\text { TSH }\end{array}$ & $\begin{array}{l}0.367 \\
0.265 \\
0.166\end{array}$ & $\begin{array}{l}+4.55 \\
+3.32 \\
+2.06\end{array}$ & $\begin{array}{l}<0.001 \\
0.001 \\
0.042\end{array}$ & $23.40 \%$ & 12.32 & $3 / 121$ & $<0.001$ \\
\hline $\begin{array}{l}\text { \#4. zSDBP in healthy } \\
\text { controls }^{\star}\end{array}$ & $\begin{array}{l}\text { Body weight } \\
\text { zTC-zHDL }\end{array}$ & $\begin{array}{l}0.396 \\
0.304\end{array}$ & $\begin{array}{l}+3.13 \\
+2.55\end{array}$ & $\begin{array}{l}0.002 \\
0.014\end{array}$ & $34.8 \%$ & 14.70 & $2 / 55$ & $<0.001$ \\
\hline $\begin{array}{l}\text { \#5 zSDBP in mood } \\
\text { disorder patients }\end{array}$ & $\begin{array}{l}\text { Antihypertensive drugs } \\
\text { NOSTOX } \\
\text { Body weight }\end{array}$ & $\begin{array}{l}0.385 \\
0.349 \\
0.246\end{array}$ & $\begin{array}{l}+4.37 \\
+4.00 \\
+2.79\end{array}$ & $\begin{array}{l}<0.001 \\
<0.001 \\
0.007\end{array}$ & $36.9 \%$ & 16.17 & $3 / 83$ & $<0.001$ \\
\hline
\end{tabular}


SBP: systolic blood pressure; zSDBP: sum of the $z$ transformation of systolic and diastolic blood pressures.

NOSTOX or zLOOH+zAOPP+zNOx+zSOD: sum of z transformations of LOOH (lipid hydroperoxides) + z AOPP (advanced oxidation protein products) + z NOx (nitric oxide metabolites) + z SOD (superoxide dismutase).

ZTRY-zHDL: reflects the atherogenic index of plasma computed as z triglycerides - z high-density-lipoprotein cholesterol; zTC-zHDL: reflects Castelli risk index 1 and is computed as z total cholesterol - zHDL; HOMA2IR: homeostasis model assessment of insulin resistance; TSH: thyroid-stimulating hormone.

*These regression analyses are conducted in selected study groups after replacing missing values with series means. 
Table 5. Results of neural networks (NN) with blood pressure data as output variables and biomarkers as input variables

\begin{tabular}{|c|c|c|c|c|}
\hline & Models & $\begin{array}{c}\text { NN\#1 } \\
\text { zSDBP }\end{array}$ & $\begin{array}{c}\text { NN\#2 } \\
\text { SBP }\end{array}$ & $\begin{array}{l}\text { NN\#3 } \\
\text { DBP }\end{array}$ \\
\hline \multirow{2}{*}{ Input Layer } & Number of units & 8 & 8 & 8 \\
\hline & Rescaling method & Normalized & Normalized & Normalized \\
\hline \multirow{4}{*}{$\begin{array}{l}\text { Hidden } \\
\text { layers }\end{array}$} & Number of hidden layers & 2 & 2 & 1 \\
\hline & Number of units in hidden layer 1 & 7 & 7 & 7 \\
\hline & Number of units in hidden layer 2 & 5 & 5 & 3 \\
\hline & Activation Function & $\begin{array}{c}\text { Hyperbolic } \\
\text { tangent }\end{array}$ & $\begin{array}{c}\text { Hyperbolic } \\
\text { tangent }\end{array}$ & $\begin{array}{c}\text { Hyperbolic } \\
\text { tangent }\end{array}$ \\
\hline \multirow{4}{*}{$\begin{array}{l}\text { Output } \\
\text { layer }\end{array}$} & Dependent variables & zSDBP & SBP & DBP \\
\hline & Number of units & 1 & 1 & 1 \\
\hline & Activation function & Identity & $\begin{array}{c}\text { Hyperbolic } \\
\text { tangent }\end{array}$ & Identity \\
\hline & Error function & Sum of squares & Sum of squares & Sum of squares \\
\hline \multirow{2}{*}{ Training } & Sum of squares error term & 22.315 & 4.645 & 23.770 \\
\hline & Relative error & 0.603 & 0.709 & 0.670 \\
\hline \multirow{2}{*}{ Testing } & Sum of Squares error & 9.938 & 1.354 & 15.569 \\
\hline & Relative error & 0.621 & 0.769 & 0.792 \\
\hline \multirow{2}{*}{ Holdout } & Relative error & 0.990 & 0.913 & 0.804 \\
\hline & Correlation with predicted value & 0.634 & 0.547 & 0.545 \\
\hline
\end{tabular}

ZSDBP: sum of the $z$ transformation of systolic and diastolic blood pressures.

SBP and DBP: systolic and diastolic blood pressure, respectively. 


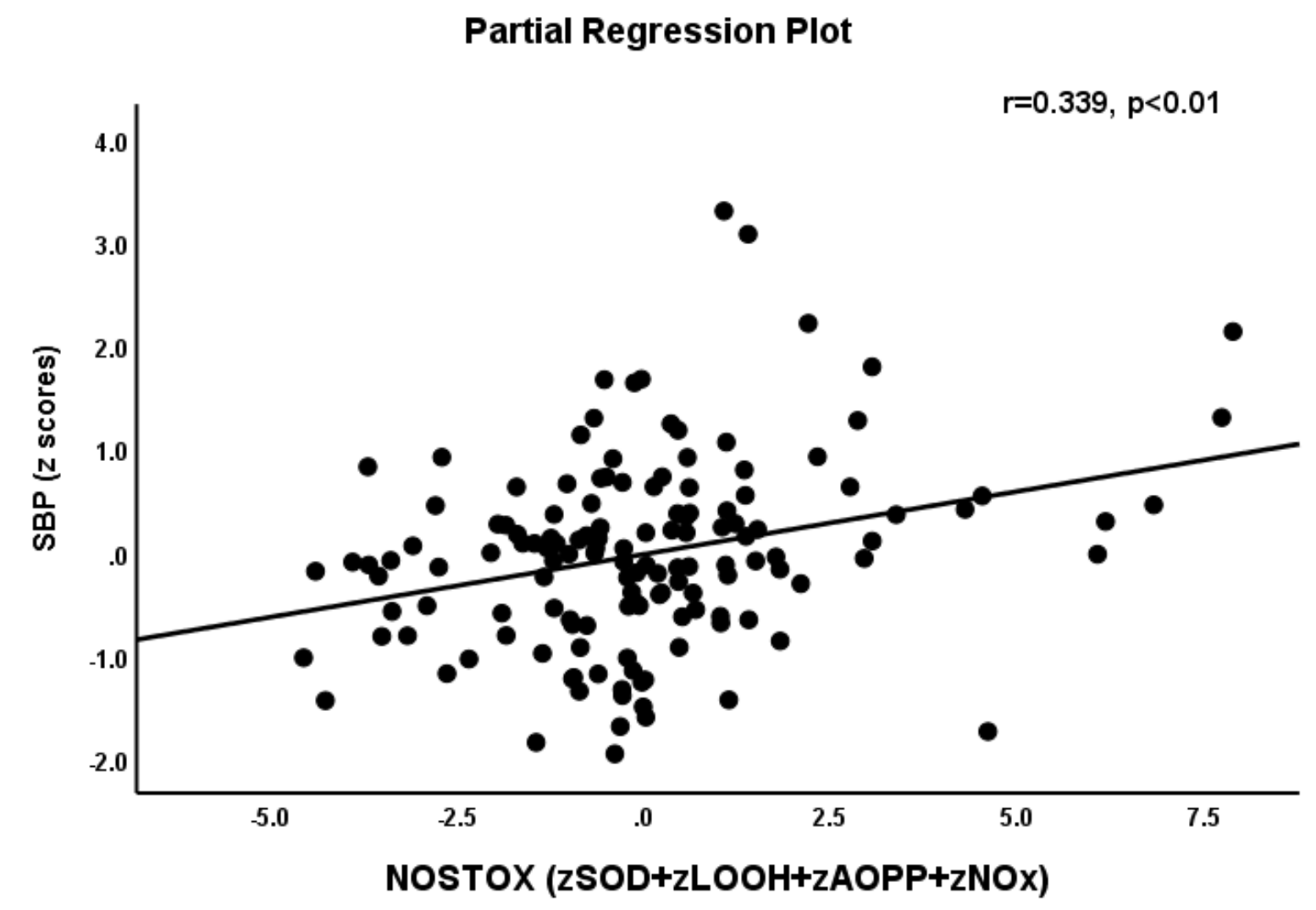

Figure 1. Partial regression of systemic blood pressure on the NOSTOX index score, indicating nitro-oxidative stress and computed as sum of $\mathrm{z}$ transformations of LOOH (lipid hydroperoxides) $+\mathrm{z}$ AOPP (advanced oxidation protein products) $+\mathrm{z}$ NOx (nitric oxide metabolites) + z SOD (superoxide dismutase). 


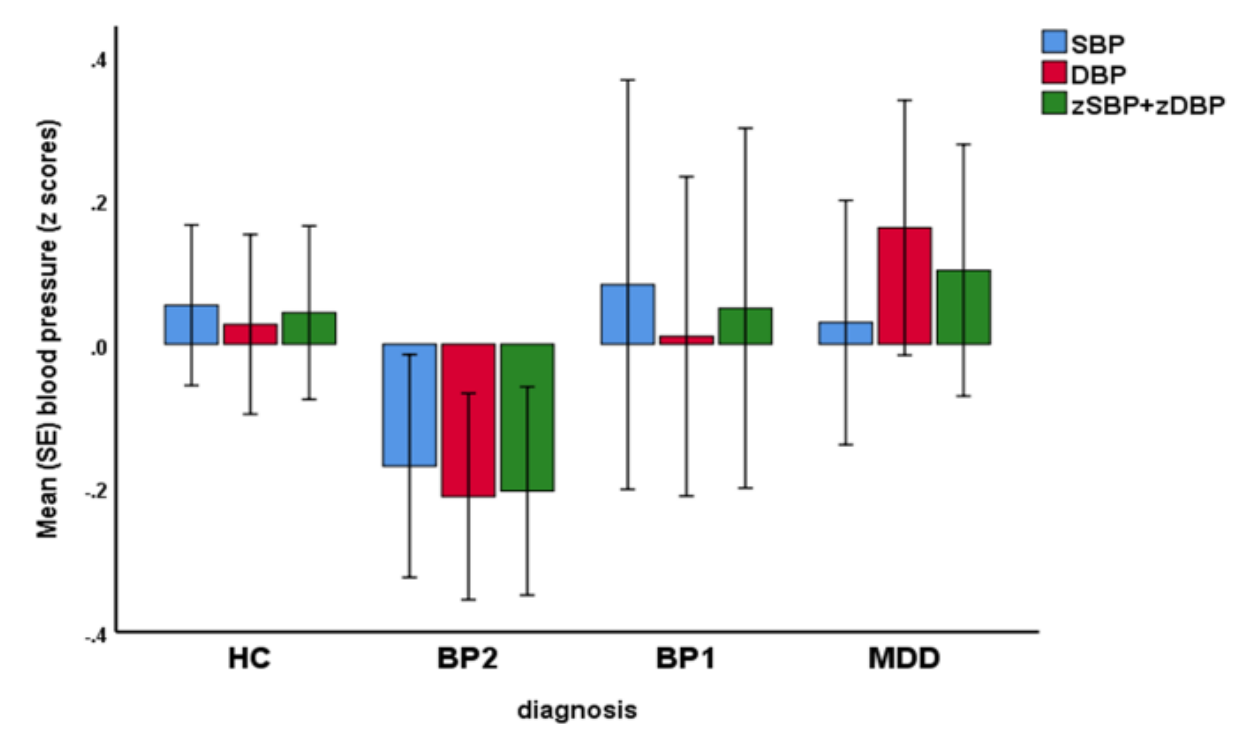

Figure 2. Bar diagram with the $\mathrm{z}$ transformed scores of systolic (SBP) and diastolic (DBP) blood pressure measurements as well as the integrated zSBP+zDBP index in healthy controls (HC), and patients with bipolar 1 (BP1) and BP2 disorder and major depression (MDD). 


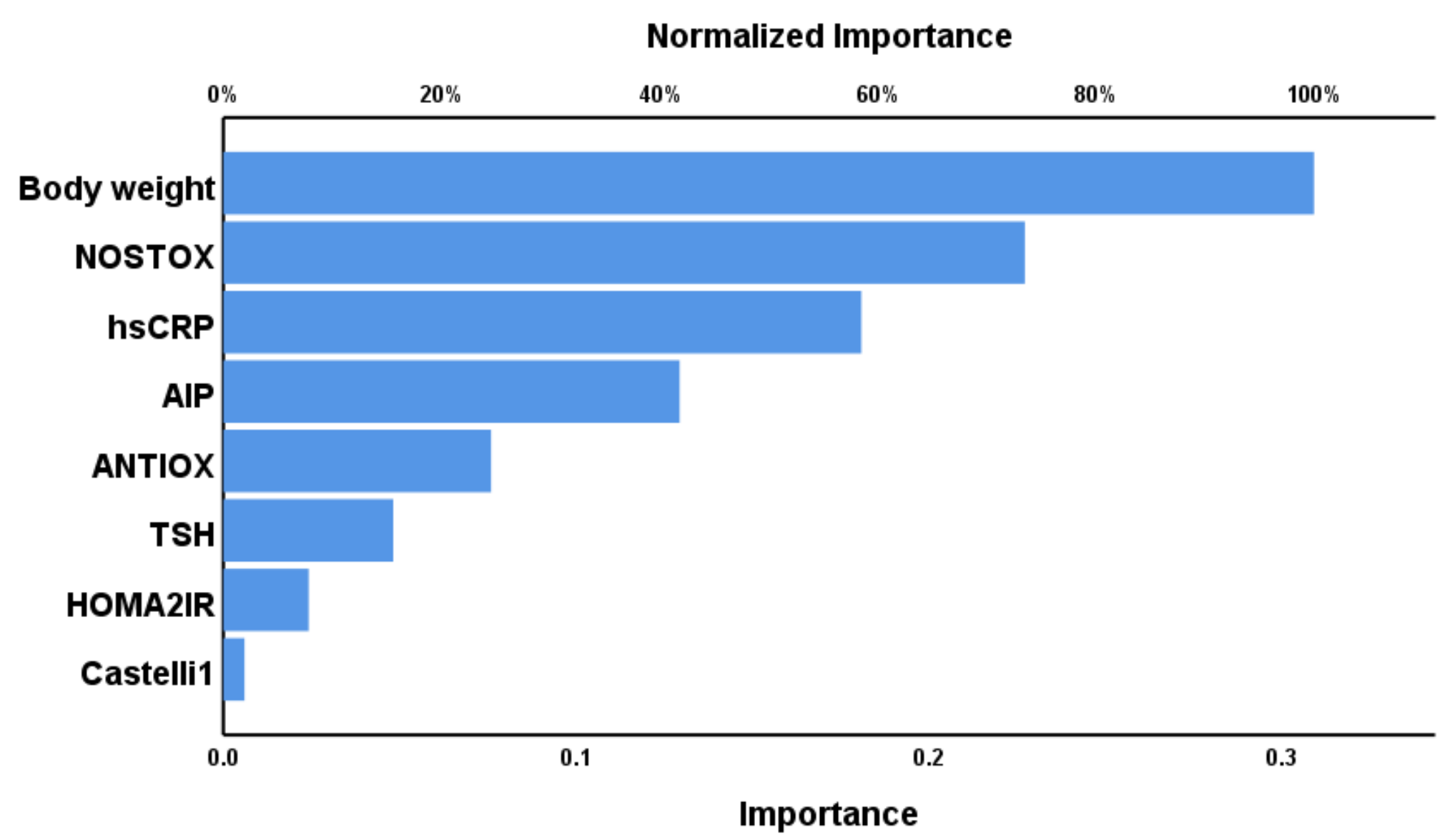

Figure 3 Results of a neural network model showing the relative importance chart with an integrated index of blood pressure ( $z$ systolic $+z$ diastolic blood pressure) as output variable. Shown are the importances of the input variables. NOSTOX (nitro-oxidative stress toxicity index); hSCRP: high sensitive C-reactive protein C; AIP: reflecting the atherogenic index of plasma; ANTIOX: an index of antioxidant capacity; TSH: basal thyroid hormone stimulating hormone; HOMA2IR: index of insulin resistance; Castelli: reflecting the Castelli risk index 1. 


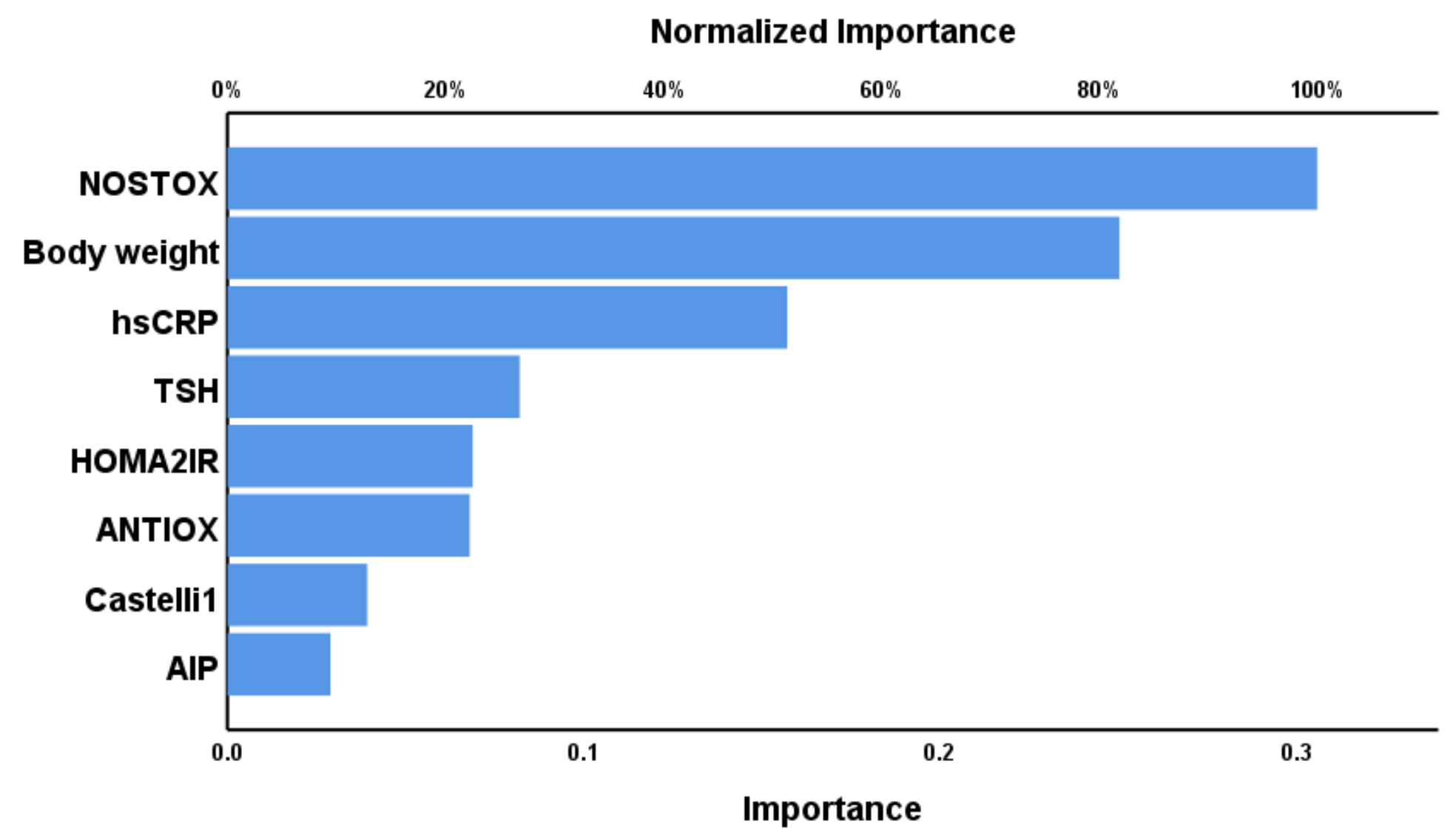

Figure 4. Results of a neural network model showing the relative importance chart with systolic blood pressure as output variable. Shown are the importances of the input variables. NOSTOX (nitro-oxidative stress toxicity index); hSCRP: high sensitive C-reactive protein C; AIP: reflecting the atherogenic index of plasma; ANTIOX: an index of antioxidant capacity; TSH: basal thyroid hormone stimulating hormone; HOMA2IR: index of insulin resistance; Castelli: reflecting Castelli risk index 1. 


\section{Normalized Importance}

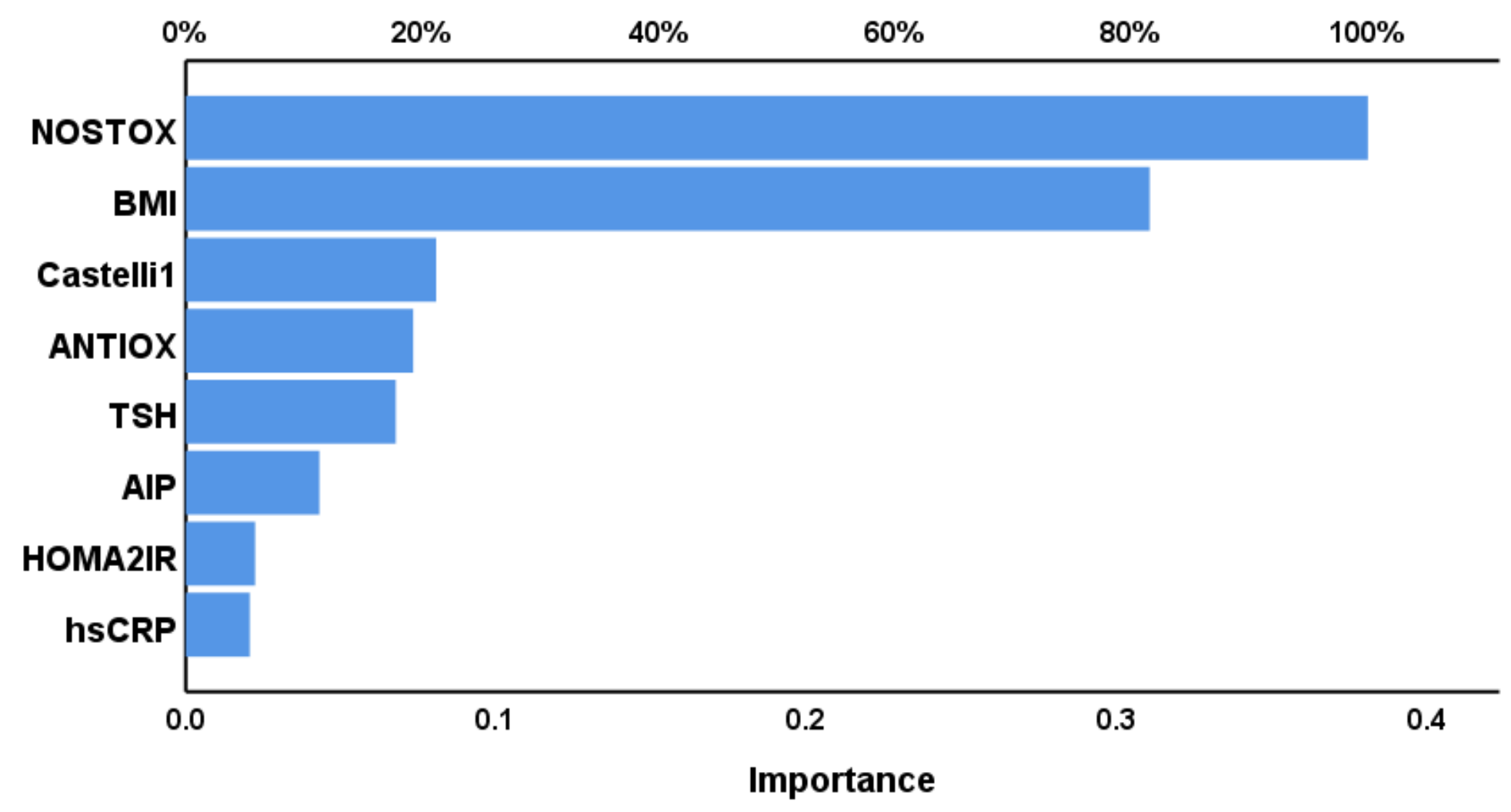

Figure 5. Results of a neural network model showing the relative importance chart with diastolic blood pressure as output variable. Shown are the importances of the input variables. NOSTOX (nitro-oxidative stress toxicity index); hSCRP: high sensitive C-reactive protein C; AIP: reflecting the atherogenic index of plasma; ANTIOX: an index of antioxidant capacity; TSH: basal thyroid hormone stimulating hormone; HOMA2IR: index of insulin resistance; Castelli: reflecting Castelli risk index 1. 